\title{
Predictors of mortality among patients with type 2 diabetes in Jordan
}

\author{
Fadia Abdallah Mayyas ${ }^{1 *}$ (D) and Khalid Shaker Ibrahim²
}

\begin{abstract}
Background: Diabetes Mellitus (DM) is a common metabolic disease associated with increased risk of mortality. Objective: The aim of this study was to examine predictors of mortality among patients with type 2 diabetes in the north of Jordan.

Methods: Electronic data files for diabetes patients admitted between the period of 2014-2018 at a tertiary center in the north of Jordan were reviewed. Patient's characteristics, clinical and laboratory data, use of medications and mortality rate were collected.

Results: Mean age of patients ( $n=957$ ) was $60.99 \pm 0.37$ (mean \pm sem). Most of patients had multiple risk factors and underlying cardiovascular diseases (CVDs). Mortality rate was 10.1\%. Univariate predictors of mortality included age, chronic kidney disease (CKD), acute kidney injury, hypertension, heart failure (HF), coronary artery disease, venous thromboembolism (VTE), stroke, atrial fibrillation (AF), and chronic obstructive pulmonary disease (COPD). As the number of CVDs increases, mortality rate also increases (Odd ratio 2.0, $p<0.0001$ ). Use of insulin, aspirin, ACEi/ ARBS, beta blockers, and diuretics were also associated with mortality. Fasting glucose and percentage of glycated hemoglobin were not associated with mortality. By multivariable logistic regression analysis adjusting for confounders and collinearity; age, HF, AF, COPD, VTE, and CKD were associated with mortality.

Conclusion: Key risk factors of mortality are CVDs and CKD indicating that the primary step of management should focus on optimizing risk factors to prevent diabetes complications and death.
\end{abstract}

Keywords: Diabetes mellitus, Mortality, Cardiovascular diseases, Jordan, Chronic kidney disease

\section{Background}

Diabetes Mellitus (DM) is a common metabolic disease associated with substantial increase of mortality [1]. DM is a significant risk factor for cardiovascular diseases (CVDs), kidney diseases and other complications [2]. In a national study in USA, DM was associated with a $16 \%$ increase in all-cause mortality and about $18 \%$ of CVDs mortality [2]. Myocardial infarction is the leading cause of mortality among diabetes patients [3]. Thus, measures to reduce death rely primarily on improving glycemic

\footnotetext{
* Correspondence: famayyas@just.edu.jo

'Department of Clinical Pharmacy, Faculty of Pharmacy, Jordan University of Science and Technology, 3030, Irbid 22110, Jordan

Full list of author information is available at the end of the article
}

control to decrease DM complications and modifying risk factors especially in those with CVDs [3]. Early studies between 1990 and 2010 in the Middle East and North Africa found that both DM and CVDs were the leading causes of mortality; responsible for nearly 1 million deaths annually $[4,5]$. In these countries, suboptimal diet and high blood pressure were the leading risk factors for cardiometabolic disease mortality; accounting for about $50-70 \%$ of deaths, followed by elevated body mass index (BMI) and fasting plasma glucose [6]. Recent data on risk factors of mortality among patients with diabetes are lacking in the Middle East region.

Jordan has one of the highest smoking and obesity prevalence rates in the region [7]. Both factors closely

(c) The Author(s). 2021 Open Access This article is licensed under a Creative Commons Attribution 4.0 International License, which permits use, sharing, adaptation, distribution and reproduction in any medium or format, as long as you give appropriate credit to the original author(s) and the source, provide a link to the Creative Commons licence, and indicate if changes were made. The images or other third party material in this article are included in the article's Creative Commons licence, unless indicated otherwise in a credit line to the material. If material is not included in the article's Creative Commons licence and your intended use is not permitted by statutory regulation or exceeds the permitted use, you will need to obtain permission directly from the copyright holder. To view a copy of this licence, visit http://creativecommons.org/licenses/by/4.0/. The Creative Commons Public Domain Dedication waiver (http://creativecommons.org/publicdomain/zero/1.0/) applies to the data made available in this article, unless otherwise stated in a credit line to the data. 
linked to risk of cardiometabolic diseases. DM is very common in Jordanian population accounting for signifcant mortality [8]. A previous study in Jordan has found that prevalence of type $2 \mathrm{DM}$ and impaired fasting glucose was 17.1 and $7.8 \%$, respectively, with about $54 \%$ of patients with unsatisfactory glycemic control [9]. No previous studies have assessd risk factors of mortality among patients with diabetes in Jordan.

The aim of this study was to examine risk factors and predictors of mortality among patients with type 2 diabetes at a primary tertiary center in the north of Jordan.

\section{Methods}

Study participants.

This study includes patients with type $2 \mathrm{DM}$ admitted to the outpatients' internal medicine clinic at King Abdullah University Hospital (KAUH). Diabetes was established by fasting plasma glucose (FPG) $\geq 126 \mathrm{mg} / \mathrm{dl}(\geq 7$ $\mathrm{mmol} / \mathrm{L}$ ) and/or glycated hemoglobin (HbA1c) $\geq 6.5 \%$ ( $\geq 48 \mathrm{mmole} / \mathrm{mol}$ ) [10].

Patient's medical files were reviewed electronically. All patients admitted to the hospital between 2014 and 2018 period with documented type 2 diabetes were included. Data were extracted retrospectively for each patient, including patient's demographic, clinical, and laboratory characteristics. This study was approved by the institutional review board of KAUH and Jordan University of Science and Technology (JUST) (\# 295/2014). All procedures were performed in accordance with the ethical standards of the Helsinki Declaration.

Patients underlying comorbidities were established according to standard guidelines and documented in patients' electronic records. Hypertension (HT) was documented by a blood pressure of 140/90 or current use of antihypertensive medications [11]. Coronary artery disease (CAD) was documented as $\geq 50 \%$ stenosis in one of the main coronaries or positive stress testing [12]. Heart failure (HF) was established according to the ACC/AHA guidelines [13]. History of atrial fibrillation (AF) was established according to the ACC/AHA guidelines [14]. Venous thromboembolism (VTE) was established by laboratory tests and diagnostic imaging [15] as documented in the patients' files. Chronic obstructive pulmonary disease (COPD) was established according to the Global Initiative for Chronic Obstructive Lung Disease (GOLD) [16]. Chronic kidney disease (CKD) was established by a decline in the glomerular filtration rate as described in the KDIGO 2012 clinical practice guidelines for the evaluation and management of CKD [17]. Moderate and severe albuminuria were documented regardless of presence of symptomatic CKD. Moderate increase in albuminuria (microalbuminuria) was established when at least two albuminuria readings were $>30 \mathrm{mg} / \mathrm{dl}$ in random urine samples that were 3 to
6 months apart, whereas severe albuminuria (macroalbuminuria) was documented when readings were $>300 \mathrm{mg} / \mathrm{dl}$ [18]. Laboratory data of lipids, glucose, kidney function and echocardiography were obtained and evaluated as risk factors of mortality. Last measured laboratory readings were considered for analysis.

Patients drug profile was revised to assess use of medications as predictors of mortality. All-cause mortality was documented electronically for diabetes patients who died in the period of 2014 to 2018.

\section{Statistical analysis}

Data are presented as meam \pm sem for continuous variables and percentages for categorical variables $(n=957)$. Univariate analysis for predictors of mortality was carried out using chi-square test for dichotomous variables, whereas logistic regression was used for categorical variables with more than 2 levels and continuous variables. Multivariable logistic regression using stepwise selection was used to assess independent predictors of mortality among diabetes patients. Univariate predictors of $p$ value $<0.25$ were entered in the model with an exit $p$ value of $>0.2$. Collinearity was tested by evaluating the correlation between independent variables. Statistical analysis was performed using JMP11, USA. A $p$ value of $<0.05$ was considered statistically significant.

\section{Results}

\section{Patients characteristics}

Table 1 represents characteristics of study population. A total of 957 patients with type $2 \mathrm{DM}$ were included in this study during the period of 2014 to 2018. Average age of patients was $60.99 \pm 0.37$ (mean \pm sem). About half of them were male and most of them had multiple risk factors and underlying morbidities. HT, CAD, peripheral artery disease (PAD), HF, stroke, history of AF, and VTE were present in 82.4, 49.1, 3.9, 10.4, 12.4, 4.9 and $2.2 \%$ of patients; respectively. Body mass index was documented for only 171 patients with mean of $32.33 \pm 1.49(\mathrm{Kg} / \mathrm{m} 2)$.

Average left ventricular ejection fraction (LVEF) was normal among patients (mean \pm sem $=55.13 \pm 0.003$ ). About $3.03 \%$ of patients had COPD. One third of patients had microalbuminuria (31.8\%), with $12 \%$ had CKD and $19.5 \%$ had acute kidney injury (AKI). All patients were on oral hypoglycemic drugs (OHA, 96.8\%) and/or insulin therapy (63.1\%). Most of patients were undercontrolled and $93.4 \%$ of them had an $\mathrm{HbA1C} \geq 7 \%$ ( $\geq 53 \mathrm{~mol} / \mathrm{mole}$ ). All patients were on multiple medications to control DM or underlying comorbidities. Aspirin, statin, angiotensin converting enzyme inhibitors/ receptor blockers (ACEi/ARBs) and beta blockers were used by about $82.9,85.5,77.4$ and $72.4 \%$ of patients; respectively. A total of 97 patients died between 2014 and 2018 with a mortality rate of $10.1 \%$. 
Table 1 Patients' characteristics

\begin{tabular}{ll}
\hline & $\boldsymbol{N}=\mathbf{9 5 7}$ \\
\hline Patients characteristics & \\
Age, years & $60.99 \pm 0.37$ \\
Male gender & $482(50.40)$ \\
BMI (Kg/m2), $n=171$ & $32.33 \pm 1.49$ \\
Hx of hypertension & $789(82.44)$ \\
Hx of heart failure & $99(10.35)$ \\
Hx of CAD & $470(49.11)$ \\
Hx of PAD & $38(3.97)$ \\
Hx of stroke/TIA & $119(12.43)$ \\
Hx of VTE & $21(2.19)$ \\
Hx of AF & $47(4.91)$ \\
Hx of CKD & $115(12.02)$ \\
Hx of AKI & $163(19.47)$ \\
Dialysis & $24(2.50)$ \\
Hx of COPD & $29(3.03)$
\end{tabular}

Diabetes mellitus

Type 2

Diabetic nephropathy

DKA

Controlled DM, HbA1c $<7 \%$

Duration of DM, yrs.

NA

\section{Hx of smoking}

Current smoking

X smoker

NA

Mortality

Lab tests (mg/dl)

Low Density Lipoprotein (LDL)

High Density Lipoprotein (HDL)

Triglyceride

Total cholesterol (Tch)

Fasting plasma glucose

HbA1c \% (mmole/mole)

Creatinine level (mg/dl)

Microalbuminuria

Macroalbuminuria

\section{Echocardiographic data}

Left ventricular ejection fraction (LVEF), \%

atrial size, $\mathrm{cm}$

$957(100.0)$

41 (4.28)

$12(1.43)$

$63(6.65)$

$7.93 \pm 0.21$

$42(4.38)$

$149(15.56)$

76 (7.94)

424 (44.30)

97 (10.14)

$134.82 \pm 2.17$

$42.09 \pm 0.64$

$267.77 \pm 8.29$

$207.04 \pm 2.52$

$265.58 \pm 3.71$

$10.19 \pm 0.078$

$1.59 \pm 0.060$

304 (31.77)

$154(16.11)$

$55.13 \pm 0.003$

$3.88 \pm 0.0175$

Use of medications, $\mathbf{n}(\%)$

ACEIs/ARBs

$741(77.43)$

Aldosterone antagonists

Thiazide diuretics
Table 1 Patients' characteristics (Continued)

\begin{tabular}{ll}
\hline & $\boldsymbol{N}=\mathbf{9 5 7}$ \\
\hline Loop diuretics & $372(38.87)$ \\
Beta blockers & $693(72.41)$ \\
Digoxin & $67(7.00)$ \\
Statins & $818(85.47)$ \\
Oral Hypoglycemic drugs & $926(96.76)$ \\
Insulin & $604(63.11)$ \\
Aspirin & $793(82.86)$
\end{tabular}

Values are presented as mean \pm SEM, and percentages $\mathrm{N}(\%)$ for categorical variables. $B M I$ body mass index, $C A D$ coronary artery disease, $P A D$ peripheral artery disease, TIA transient ischemic attack, $A F$ atrial fibrillation, VTE venous thromboembolism, CKD chronic kidney disease, $A K l$ acute kidney injury, COPD chronic obstructive pulmonary disease, $\mathrm{Hx}$ history, $\mathrm{HbA1c}$ glycosylated hemoglobin, DKA diabetic ketoacidosis, $A C E l$ angiotensin converting enzyme inhibitor, $A R B s$ angiotensin-II receptor blockers, NA not available. Unit for lipids and glucose is $\mathrm{mg} / \mathrm{dl}$

\section{Predictors of mortality among diabetes patients}

We have evaluated factors associated with increased mortality (Table 2). By univariate analysis, age (Odd ratio (OR) 1.06), HT (OR 7.54), HF (OR 3.95), CAD (OR 1.62), VTE (OR 3.71), stroke (OR 2.47), AF (OR 5.28), and COPD (OR 3.59) were all associated with increased mortality rate $(p<0.05)$. As the number of cardiovascular comorbidities increases, mortality rate also increases (OR 2.00, $p<0.0001$ ). Current smoking, gender and PAD were not associated with mortality $(p>0.05)$. Diabetic nephropathy is a common DM complication and was associated with mortality, similar to macro and microalbuminuria $(P<0.0001)$. Both CKD (OR 4.61) and AKI (OR 8.75) were strongly associated with mortality including those who underwent dialysis $(p<0.0001)$. Diabetes ketoacidosis (DKA) is an acute complication of DM and was also associated with mortality. Neither lipid profile nor glucose or $\mathrm{HbA} 1 \mathrm{c} \%$ levels were associated with mortality $(p>$ 0.05 ). Because $94 \%$ of patients were under controlled with mean $\mathrm{HbA} 1 \mathrm{c} \%$ of $10.19 \pm 0.078$, we have stratified patients based on $\mathrm{HbA} 1 \mathrm{c} \%$ values into categories and evaluated their relation to mortality. $\mathrm{HbA} 1 \mathrm{c} \%$ ranges were: $<8,8-<9.5,9.5-<11,11-<13, \geq 13$. No association was found between any of the HbA1c\% categories and mortality, $p<0.05$ for all. Duration of DM in years was not associated with mortality $(p=$ 0.24). We have further explored relation of duration of DM to mortality by stratifying patients into categories $\leq 6$ vs. $>6$ years. DM duration $>6$ years was associated with mortality ( $p=0.0183$, OR 1.67 (95\% CI: 1.09-2.57). Patients with significant increase in glucose level are usually controlled by insulin therapy. Use of insulin (OR 1.77, $p=0.0167$ ) and use of combination of insulin and OHA therapy (OR 1.68, $p=$ 0.0252 ) were associated with mortality, whereas use of 
Table 2 Univariate predictors of mortality among patients with type 2 diabetes

Response $=$ Mortality,$N=957$

\begin{tabular}{|c|c|c|c|}
\hline & Confidence interval (95\%) & $P$ value & Odd Ratio \\
\hline Age, yrs. & $1.0389-1.0831$ & $<0.0001^{*}$ & 1.0630 \\
\hline Male Gender & $0.6908-1.6004$ & 0.8147 & 1.0515 \\
\hline $\mathrm{BMI}(\mathrm{Kg} / \mathrm{m} 2), \mathrm{n}=171$ & $0.9547-1.0621$ & 0.7221 & 1.0096 \\
\hline Current smoking & $0.4492-1.4399$ & 0.4630 & 0.8043 \\
\hline Hypertension & $4.3030-10.754$ & $0.0007^{*}$ & 7.5423 \\
\hline HF & $2.3724-6.5696$ & $<0.0001^{*}$ & 3.9479 \\
\hline CAD & $1.0547-2.4793$ & $0.0264^{*}$ & 1.6171 \\
\hline PAD & $0.6947-4.1895$ & 0.2386 & 1.7060 \\
\hline VTE & $1.4064-9.8091$ & $0.0046^{*}$ & 3.7142 \\
\hline Stroke/TIA & $1.4797-4.1347$ & $0.0004^{*}$ & 2.4735 \\
\hline AF & $2.7713-10.0684$ & $<0.0001^{*}$ & 5.2823 \\
\hline COPD & $1.5455-8.3445$ & $0.0016^{*}$ & 3.5912 \\
\hline CKD & $2.8518-7.4478$ & $<0.0001^{*}$ & 4.6087 \\
\hline Number of CVD comorbidities & $1.6666-2.4219$ & $<0.0001^{*}$ & 2.0005 \\
\hline Diabetic nephropathy & $2.2950-9.2144$ & $<0.0001^{*}$ & 4.5986 \\
\hline Macroalbuminuria & $2.9248-7.1905$ & $<0.0001^{*}$ & 4.5860 \\
\hline Microalbuminuria & $1.7395-4.0673$ & $<0.0001^{*}$ & 2.6599 \\
\hline AKI & $5.5478-13.8176$ & $<0.0001^{*}$ & 8.7554 \\
\hline Dialysis & $1.9739-11.3898$ & $0.0001^{*}$ & 4.7415 \\
\hline DKA & $0.0901-5.5301$ & 0.7390 & 0.7095 \\
\hline DM duration & $0.9868-1.0496$ & 0.2434 & 1.0189 \\
\hline DM duration, $\leq>6$ yrs. & $1.0940-2.5705$ & $0.0183^{*}$ & 1.6696 \\
\hline Controlled DM & $0.4938-2.5243$ & 0.7910 & 1.1165 \\
\hline LVEF & $0.0014-0.1248$ & $0.0001^{*}$ & 0.0129 \\
\hline LA size, $\mathrm{cm}$ & $2.6298-6.3121$ & $<0.0001^{*}$ & 4.0400 \\
\hline Cr level & $1.2072-1.4613$ & $<0.0001^{*}$ & 1.3246 \\
\hline LDL & $0.9970-1.0038$ & 0.7178 & 1.0006 \\
\hline $\mathrm{HDL}$ & $0.9756-1.0053$ & 0.3166 & 0.9921 \\
\hline Triglyceride & 0.9979-1.0002 & 0.1734 & 0.9991 \\
\hline Total Cholesterol & $0.9971-1.0030$ & 0.8960 & 1.0001 \\
\hline Fasting plasma glucose & $0.9967-1.0011$ & 0.4035 & 0.9990 \\
\hline $\mathrm{HbA} 1 \mathrm{c}, \%$ & $0.9714-1.1523$ & 0.1865 & 1.0591 \\
\hline Use of Insulin & $1.1038-2.8562$ & $0.0167^{*}$ & 1.7756 \\
\hline Insulin alone & $0.3733-4.3551$ & 0.6975 & 1.2750 \\
\hline Use of $\mathrm{OHA}$ & $0.3145-3.5348$ & 0.9315 & 1.0544 \\
\hline $\mathrm{OHA}$ alone & $0.3623-0.9379$ & $0.0248^{*}$ & 0.5830 \\
\hline Combination of insulin and $\mathrm{OHA}$ & $1.0627-2.6654$ & $0.0252^{*}$ & 1.6830 \\
\hline ACEi/ARB & $0.8771-2.6831$ & 0.1311 & 1.5340 \\
\hline Beta blockers & $1.5761-5.4684$ & $0.0004^{*}$ & 2.9358 \\
\hline Aldosterone antagonists & $1.3569-4.4480$ & $0.0023^{*}$ & 2.4567 \\
\hline Thiazide Diuretics & $0.9824-2.2912$ & 0.0591 & 1.5003 \\
\hline Loop Diuretics & $2.5343-6.3904$ & $<0.0001^{*}$ & 4.0639 \\
\hline Statins & $0.7100-2.6321$ & 0.3478 & 1.3671 \\
\hline
\end{tabular}


Table 2 Univariate predictors of mortality among patients with type 2 diabetes (Continued)

\begin{tabular}{llll}
\hline Response $=$ Mortality, $\boldsymbol{N}=\mathbf{9 5 7}$ & & & \\
\hline & Confidence interval (95\%) & $\boldsymbol{P}$ value & Odd Ratio \\
\hline Digoxin & $1.5325-5.2717$ & $0.0006^{*}$ & 2.8424 \\
lon channel blockers & $0.8954-8.7702$ & 0.0649 & 2.8023 \\
Aspirin & $1.0594-4.3620$ & $0.0303^{*}$ & 2.1497 \\
\hline
\end{tabular}

Odd ratio is per unit change in regressor. ${ }^{*}$ is a $p$ value $<0.05$. BMI body mass index, CAD coronary artery disease, $P A D$ peripheral artery disease, $T I A$ transient ischemic attack, $A F$ atrial fibrillation, VTE venous thromboembolism, CKD chronic kidney disease, AKI acute kidney injury, COPD chronic obstructive pulmonary disease; number of cardiovascular morbidities include HT, HF, CAD, PAD and stroke, Hx history, HbA1c glycosylated hemoglobin, DKA diabetic ketoacidosis, ACEI angiotensin converting enzyme inhibitor, ARBs angiotensin-II receptor blockers

OHA alone is associated with reduced mortality (OR 0.583, $p=0.0248)$. Reduced LVEF and enlarged left atria were both associated with mortality $(p<0.0001)$. Patients with DM have several underlying CVDs that require management by drug therapies. Use of beta blocker, aldosterone antagonists, digoxin, loop diuretics and aspirin were all associated with mortality $(p<0.05)$, whereas use of statin and ACEi/ARBs were not associated with mortality (Table 2 ).

\section{Independent predictors of mortality among diabetes patients}

We have performed multivariable logistic regression analysis to evaluate independent risk factors associated with mortality adjusting for possible confounders (Table 3). By step wise analysis, both LVEF and LA size were associated with mortality $(<0.05)$ but were not included in the model due to collinearity with HF. As creatinine level, albuminuria, nephropathy and dialysis were collinear with CKD, they were also excluded from the model. Both use of aldosterone antagonists and loop diuretics were associated with mortality, but due to collinearity with HF and HT, they were not included in the final model. By multivariable logistic regression adjusting

Table 3 Multivariate predictors of mortality among patients with type 2 diabetes

\begin{tabular}{llll}
\hline Response $=$ Mortality, $\mathbf{N}=\mathbf{9 5 7}$ & & \\
\hline & $\begin{array}{l}\text { Confidence interval } \\
\mathbf{( 9 5 \% )}\end{array}$ & $\boldsymbol{P}$ value & $\begin{array}{l}\text { Odd } \\
\text { Ratio }\end{array}$ \\
\hline Age, yrs. & $1.0125-1.0610$ & $0.0028^{*}$ & 1.0362 \\
Hypertension & $0.9158-6.4258$ & 0.1106 & 2.1747 \\
Heart failure & $1.1585-3.7228$ & $0.0121^{*}$ & 2.1065 \\
Venous & $0.9932-8.7748$ & $0.0372^{*}$ & 3.1326 \\
Thromboembolism & & & \\
Stroke/TIA & $0.9213-2.9071$ & 0.0818 & 1.6624 \\
Atrial Fibrillation & $1.1680-5.3020$ & $0.0155^{*}$ & 2.5349 \\
COPD & $1.1298-7.4443$ & $0.0199^{*}$ & 3.3044 \\
Chronic Kidney Disease & $1.6031-4.6813$ & $0.0002^{*}$ & 2.7593 \\
Use of Insulin & $0.8860-2.5193$ & 0.1433 & 1.4749 \\
\hline
\end{tabular}

Odd ratio is per unit change in regressor. TIA transient ischemic attack, COPD Chronic obstructive pulmonary disease for other variables and collinearity, age, HF, AF, COPD, VTE, and CKD were significantly and independently associated with mortality. History of AKI was strongly and independently associated with mortality (OR 5.82, $p<$ 0.0001). However, because presence of CKD, HT, HF or stroke could predispose to AKI, AKI was removed from the model to avoid overlap between them. History of stroke/TIA was marginally significant. Use of insulin and use of combination of insulin + OHA were associated with mortality, however, insulin use was entered in the final model to avoid collinearity. HT and insulin use were not associated with mortality in the final model (Table 3). Adjusting for other variables, use of beta blocker and duration of $\mathrm{DM}>6$ years were not associated with mortality and were removed from the model $(p=0.4183, p=0.2799$; respectively). In another model, increased number of CVD indications was found significantly associated with mortality $(p<0.0001$, OR 1.7619 , 95\% CI: 1.457-2.1616).

\section{Discussion}

In the present study, we have assessed a broad number of characteristics and clinical data that might be associated with increased mortality among patients with type 2 diabetes. The prevalence of DM and its associated death are rapidly increasing in Jordan $[8,9]$. Our center is a tertiary center that provides health care for a significant number of DM patients in the Northern area of Jordan. Laboratory data of key parameters such as lipid and kidney function were assessed, in addition to use of medications.

All included patients have type $2 \mathrm{DM}$, which is associated with obesity that is common in Jordan [7]. However, obesity as indicated by BMI was not associated with mortality in our study probably because it is documented for small number of patients. DM promotes atherosclerosis and HT predisposing into HF, arrhythmia and thrombosis. Diabetes mellitus remains significantly associated with all-cause of CVD mortality [19]. CVDs are associated with 3- to 4-fold higher risk of mortality in patients with DM relative to those without DM [19]. Our findings suggest that CVDs including HT, HF, stroke, VTE and AF diseases are the primary predictors 
of mortality among patients, and the odds of mortality increase with increased number of underlying CVDs. Consistent with our findings, previous studies showed that CVDs account for most of mortality in DM patients $[4,5]$. Thus, primary prevention of CVD is a major goal among patients with DM to reduce risk of death [20]. In USA, improvement in the control of CVDs risk factors and preventive practices between 1990 to 2010 [21] was associated with a decline in the rates of DM complications [22]. In a nationwide registry, in-hospital mortality between 1997 and 2010 period remarkably decreased in DM patients, from 19.9 to $9.0 \%$, with a decrease of $6 \%$ per year of admission [2]. Although increased awareness of DM diagnosis and management is expected to improve DM outcomes and mortality rates, mortality is still significant.

Therapeutic management of DM is multifactorial process that involves targeting serum glucose, cholesterol, blood pressure goals, in addition to modifications of life style habits [23]. The percentage of HbA1c is an indicator of long term glycemic control. Patients with DM should maintain a percentage of $<7 \%$ HbA1c [24]. Increased gradient of mortality rate is associated with increased $\mathrm{HbA} 1 \mathrm{c} \%$ from $>6$ to $6.9 \%$ [19]. Interestingly, it has been found that aggressive glycemic control may also increase mortality in elderly patients [25]. However, in our study, glycemic control as indicated by the increase in $\mathrm{HbA} 1 \mathrm{c} \%$ values or categories was not associated with mortality. It is important to note that $94 \%$ of our patients were under-controlled as documented by their last measured $\mathrm{HbA} 1 \mathrm{c} \%$. The lack of association of $\mathrm{HbA} 1 \mathrm{c} \%$ with mortality may be due to the lack of wide distribution of patients over categories and limited number of controlled patients. Future studies with larger sample size may reveal a potential association.

Increased duration of diabetes is associated with development and progression of complications and comorbidities [26]. The increase in DM duration in years was not associated with mortality possibly because mean duration in our study was not long enough to promote complications. However, duration of more than 6 years was associated with mortality relative to duration less than 6 years by univariate analysis but not multivariate analysis. It has been found that longer diabetes duration $>5,10$ and 15 years is associated with proportional increase in odds of CVDs risk and mortality relative to patients with duration $<5$ years [26].

Hyperglycemia promotes metabolic changes mediating microvascular diseases secondary to atherosclerosis and other complications including neuro and nephropathy [23]. These metabolic changes involve the production of advanced glycation end products, oxidative stress and histological changes that promote glomerular sclerosis. Nephropathy is one of the most prevalent chronic complications of DM [23]. Interestingly, microalbuminuria was found associated with increased arterial stiffness, left ventricular mass and atherosclerosis in patients with type $2 \mathrm{DM}$ [27]. DM is one of the most common causes of end-stage renal disease [28]. Patients with DM and CKD are prone to hospitalization, and both AKI and CKD account for significant component of expenditure on medical care [29]. Our results documented that CKD and AKI are significant predictors of mortality in DM patients. Step wise analysis showed that microalbuminuria also predicts mortality, indicating the value of early diagnosis of nephropathy in DM patients to provide the optimal management to slow and prevent the development and the progression of CKD and AKI.

Previously, it was found that treatment with insulin with or without oral medications was a significant risk factor for all-cause and CVD mortality [30]. Similarly, by univariate analysis, we observed that use of insulin and combination of insulin with oral medications were associated with mortality, whereas use of oral medications alone is associated with reduced mortality. However, this relationship was not statistically significant when adjusting to potential confounding of other factors in the multivariable model. Although use of insulin provides effective glycemic control, it is usually used when glycemic control is not achieved by oral medications indicating disturbed glycemic status. Use of insulin may also increase risk of weight gain, hypoglycemia, metabolic syndrome and CVDs leading to mortality, especially in type $2 \mathrm{DM}$ with insulin resistance [31]. Future studies with larger sample size should provide more understanding of this relationship.

Increased mortality rate is observed among patients using diuretics, $\beta$-blockers, and other antihypertensive medications. These medications are usually prescribed for patients with elevated and persistent HT and for patients with underlying CVDs, which are risk factors of mortality. By univariate analysis, many of used medications were associated with mortality including use of beta blockers, diuretics, and aldosterone antagonists. However, due to collinearity and confounding by comorbidities, they were not associated with mortality when included in the multivariate model adjusting for underlying diseases.

\section{Limitations of the study}

This is a cross sectional study of patients with diabetes with retrospective data collection. Future follow up cohort studies are recommended to evaluate predictors of mortality over time. Our study evaluated patients' comorbidities, lab data and use of medications. Evaluation of other factors such as family income and family history of CVDs is important to better understand predictors of mortality. Most of our patients were old, and age is 
associated with cardiac and metabolic diseases. Future studies should include patients with younger ages. The study is limited by the lack of a control group. Future controlled studies with larger sample size are recommended.

\section{Conclusion}

In a large study of type $2 \mathrm{DM}$ patients in the north of Jordan, we found that key risk factors of mortality are CVDs and kidney diseases indicating that primary step of management should focus on optimizing risk factors to prevent diabetes complications and death.

\section{Acknowledgements}

None.

\section{Authors' contributions}

Fadia Mayyas: conception/design of the study, data analysis and interpretation, manuscript draft and review, tables preparation. Khalid Ibrahim: study design and data collection, data analysis, critical manuscript review. The authors read and approved the final manuscript.

\section{Funding}

This study was funded by a grant (\#295/2014) from the dean ship of research at Jordan University of Science and Technology.

\section{Availability of data and materials}

Data are presented in the manuscript. Any additional data will be available upon request from the corresponding author.

\section{Declarations}

\section{Consent of publication}

Not applicable.

\section{Ethics approval and consent to participate}

This study was approved by the institutional review board of KAUH and Jordan University of Science and Technology (JUST) (295/2014). All procedures were performed in accordance with the ethical standards of the Helsinki Declaration (1964). Informed consent was waived by the IRB due to the nature of the study (retrospective electronic data collection) and that research involves no more than minimal risk to patients and will not affect their rights. In addition, the study could not practicably be carried out without the waiver.

\section{Competing interests}

None.

\section{Author details}

'Department of Clinical Pharmacy, Faculty of Pharmacy, Jordan University of Science and Technology, 3030, Irbid 22110, Jordan. ${ }^{2}$ Princess Muna Heart Institute, King Abdullah University Hospital, Division of Cardiac Surgery, Department of General Surgery, Faculty of Medicine, Jordan University of Science and Technology, Irbid, Jordan.

Received: 2 May 2021 Accepted: 28 September 2021

Published online: 12 October 2021

\section{References}

1. Zhou JJ, Koska J, Bahn G, Reaven P. Glycaemic variation is a predictor of allcause mortality in the veteran affairs Diabetes trial. Diab Vasc Dis Res. 2019; 16(2):178-85.

2. Roffi M, Radovanovic D, Erne P, Urban P, Windecker S, Eberli FR, et al. Gender-related mortality trends among diabetic patients with ST-segment elevation myocardial infarction: insights from a nationwide registry 19972010. Eur Heart J Acute Cardiovasc Care. 2013;2(4):342-9.

3. Rao Kondapally Seshasai S, Kaptoge S, Thompson A, Di Angelantonio E, Gao $P$, Sarwar N, et al. Diabetes mellitus, fasting glucose, and risk of causespecific death. New Engl J Med. 2011;364(9):829-41.
4. Lim SS, Vos T, Flaxman AD, Danaei G, Shibuya K, Adair-Rohani H, et al. A comparative risk assessment of burden of disease and injury attributable to 67 risk factors and risk factor clusters in 21 regions, 1990-2010: a systematic analysis for the global burden of disease study 2010. Lancet. 2012;380(9859): 2224-60.

5. Lozano R, Naghavi M, Foreman K, Lim S, Shibuya K, Aboyans V, et al. Global and regional mortality from 235 causes of death for 20 age groups in 1990 and 2010: a systematic analysis for the global burden of disease study 2010. Lancet. 2012;380(9859):2095-128.

6. Afshin A, Micha R, Khatibzadeh S, Fahimi S, Shi P, Powles J, et al. The impact of dietary habits and metabolic risk factors on cardiovascular and diabetes mortality in countries of the Middle East and North Africa in 2010: a comparative risk assessment analysis. BMJ Open. 2015;5(5):e006385.

7. Al Nsour M, Al Kayyali G, Naffa S. Overweight and obesity among Jordanian women and their social determinants. East Mediterr Health J. 2013;19(12): 1014-9.

8. Jarab AS, Alqudah SG, Mukattash TL, Shattat G, Al-Qirim T. Randomized controlled trial of clinical pharmacy management of patients with type 2 diabetes in an outpatient diabetes clinic in Jordan. J Manag Care Pharm. 2012;18(7):516-26

9. Ajlouni K, Khader YS, Batieha A, Ajlouni H, El-Khateeb M. An increase in prevalence of diabetes mellitus in Jordan over 10 years. J Diabetes Complicat. 2008;22(5):317-24.

10. American Diabetes A. Standards of medical care in diabetes-2014. Diabetes Care. 2014:37(Suppl 1):S14-80.

11. James PA, Oparil S, Carter BL, Cushman WC, Dennison-Himmelfarb C, Handler J, et al. 2014 evidence-based guideline for the management of high blood pressure in adults: report from the panel members appointed to the eighth joint National Committee (JNC 8). JAMA. 2014;311(5):507-20.

12. Finn SD, Blankenship JC, Alexander KP, Bittl JA, Byrne JG, Fletcher BJ, et al. 2014 ACC/AHA/AATS/PCNA/SCAI/STS focused update of the guideline for the diagnosis and management of patients with stable ischemic heart disease: a report of the American College of Cardiology/ American Heart Association Task Force on Practice Guidelines, and the American Association for Thoracic Surgery, Preventive Cardiovascular Nurses Association, Society for Cardiovascular Angiography and Interventions, and Society of Thoracic Surgeons. J Thorac Cardiovasc Surg. 2015;149(3):e5-23.

13. Yancy CW, Jessup M, Bozkurt B, Butler J, Casey DE Jr, Colvin MM, et al. 2017 ACC/AHA/HFSA focused update of the 2013 ACCF/AHA guideline for the Management of Heart Failure: a report of the American College of Cardiology/American Heart Association task force on clinical practice guidelines and the Heart Failure Society of America. J Am Coll Cardiol. 2017; 70(6):776-803.

14. January CT, Wann LS, Alpert JS, Calkins H, Cigarroa JE, Cleveland JC Jr, et al. 2014 AHA/ACC/HRS guideline for the management of patients with atrial fibrillation: a report of the American College of Cardiology/American Heart Association task force on practice guidelines and the Heart Rhythm Society. J Am Coll Cardiol. 2014;64(21):e1-76.

15. Lim W, Le Gal G, Bates SM, Righini M, Haramati LB, Lang E, et al. American Society of Hematology 2018 guidelines for management of venous thromboembolism: diagnosis of venous thromboembolism. Blood Adv. 2018:2(22):3226-56.

16. Hess MW. The 2017 global initiative for chronic obstructive lung disease report and practice implications for the respiratory therapist. Respir Care. 2017;62(11):1492-500.

17. Levin A, Stevens PE. Summary of KDIGO 2012 CKD guideline: behind the scenes, need for guidance, and a framework for moving forward. Kidney Int. 2014;85(1):49-61.

18. Haneda M, Utsunomiya K, Koya D, Babazono T, Moriya T, Makino H, et al. A new classification of diabetic nephropathy 2014: a report from joint committee on diabetic nephropathy. Clin Exp Nephrol. 2015;19(1):1-5.

19. Raghavan S, Vassy JL, Ho YL, Song RJ, Gagnon DR, Cho K, et al. Diabetes mellitus-related all-cause and cardiovascular mortality in a National Cohort of adults. J Am Heart Assoc. 2019;8(4):e011295.

20. Zhu M, Li J, Li Z, Luo W, Dai D, Weaver SR, et al. Mortality rates and the causes of death related to diabetes mellitus in Shanghai Songjiang District: an 11-year retrospective analysis of death certificates. BMC Endocr Disord. 2015;15:45.

21. Ali MK, Bullard KM, Saaddine JB, Cowie CC, Imperatore G, Gregg EW. Achievement of goals in U.S. diabetes care, 1999-2010. New Engl J Med. 2013;368(17):1613-24. 
22. Gregg EW, Li Y, Wang J, Burrows NR, Ali MK, Rolka D, et al. Changes in diabetes-related complications in the United States, 1990-2010. N Engl J Med. 2014;370(16):1514-23.

23. Satirapoj B. Nephropathy in diabetes. Adv Exp Med Biol. 2012;771:107-22.

24. Garber AJ, Abrahamson MJ, Barzilay Jl, Blonde L, Bloomgarden ZT, Bush MA, et al. Consensus statement by the American Association of Clinical Endocrinologists and American College of endocrinology on the comprehensive type 2 Diabetes management algorithm--2016 executive summary. Endocr Pract. 2016;22(1):84-113.

25. Ying DG, Ko SH, Li YC, Chen CX. Association between intensive glycemic control and mortality in elderly diabetic patients in the primary care: a retrospective cohort study. Prim Care Diabetes. 2020;14(5):476-81.

26. Li FR, Yang HL, Zhou R, Zheng JZ, Chen GC, Zou MC, et al. Diabetes duration and glycaemic control as predictors of cardiovascular disease and mortality. Diabetes Obes Metab. 2021;23(6):1361-70.

27. Sjoblom P, Nystrom FH, Lanne T, Engvall J, Ostgren CJ. Microalbuminuria, but not reduced eGFR, is associated with cardiovascular subclinical organ damage in type 2 diabetes. Diabetes Metab. 2014;40(1):49-55.

28. Abdallah S, Ahmad AT, Batieha A, Ajlouni K. Diabetes mellitus: the leading cause of haemodialysis in Jordan. East Mediterr Health J. 2007;13(4):803-9.

29. Winocour PH. Diabetes and chronic kidney disease: an increasingly common multi-morbid disease in need of a paradigm shift in care. Diabet Med. 2018;35(3):300-5

30. McEwen LN, Karter AJ, Waitzfelder BE, Crosson JC, Marrero DG, Mangione $\mathrm{CM}$, et al. Predictors of mortality over 8 years in type 2 diabetic patients: translating research into action for Diabetes (TRIAD). Diabetes Care. 2012; 35(6):1301-9.

31. Mendez CE, Walker RJ, Eiler CR, Mishriky BM, Egede LE. Insulin therapy in patients with type 2 diabetes and high insulin resistance is associated with increased risk of complications and mortality. Postgrad Med. 2019;131(6): $376-82$.

\section{Publisher's Note}

Springer Nature remains neutral with regard to jurisdictional claims in published maps and institutional affiliations.

Ready to submit your research? Choose BMC and benefit from:

- fast, convenient online submission

- thorough peer review by experienced researchers in your field

- rapid publication on acceptance

- support for research data, including large and complex data types

- gold Open Access which fosters wider collaboration and increased citations

- maximum visibility for your research: over $100 \mathrm{M}$ website views per year

At $\mathrm{BMC}$, research is always in progress.

Learn more biomedcentral.com/submissions 